\title{
AN INVESTIGATION INTO ROCK CLIMBING EFFICIENCY
}

\author{
D. J. Rushworth \\ St. Luke's College, Exeter
}

This investigation was carried out with two aims in view. Firstly, to produce experimental evidence of the constituents of an efficient climbing style, and secondly to investigate the possibilities of skills analysis by the use of video tape, electromyograph and heart rate recordings.

For the purpose of the investigation eight students from the college were used as subjects. Four of the students were experienced rock climbers, the other four had no previous experience in the sport.

In order to eliminate the possibility of basic fitness affecting the heart rate readings in the final analysis, each subject was required to undergo a Harvard Step Test, the results of which were employed in later comparisons.

Each subject was required to climb a designated route on the artificial climbing wall at Exeter University, protected by a top rope. This route had been described by a cross being placed alongside each hold to be used.

Before performing the climb each subject was equipped with electromyograph electrodes on four muscle groups, and heart rate electrodes.

Whilst each subject performed the climb he was filmed by means of a video tape camera and recorder. The signals received from the electromyograph transmitter were fed onto the sound track of the video tape via the recorder socket, from the receiver unit. Simultaneously, a trace recording the heart rate was produced on a separate chart recorder. The recorded information was then taken to the physiology laboratory at St. Luke's College for analysis.

The results of the electromyograph recordings were fed through a demodulator unit and then displayed simultaneously with the showing of the video tape film, on a four trace oscilloscope. By observing the two screens it was possible to correlate muscular activity with actual movement. Any particularly interesting traces were transferred onto a paper trace for retention and inclusion in the completed piece of work, along with the heart rate traces.

\section{Conclusions}

\section{Conclusions relating to rock climbing efficiency.}

As a result of the analysis in the laboratory the following conclusions were made:

a. Because of its construction and resultant range of movement, the latissimus dorsi is the most important large muscle in the upper body of a rock climber.

b. The flexor muscles of the fingers and wrist are susceptible to local muscle fatigue because they work in almost continual isometric contraction.

c. If the climber stands with his body clear of the rock and with his weight over his feet the strong muscle groups of the legs can be used to provide their greatest power in a direct thrust.

d. By standing clear of the rock the climber allows himself more room in which to move his feet upwards in a relaxed position.

e. Unnecessary muscular activity can be brought about by the release of adrenalin, this results in activity even when the muscle group in question appears to be in a relaxed position.

f. Fitness is relevant to rock climbing, but progresses through climbing and is only relevant if coupled with technique.

g. An efficient climbing style is one in which the climber is able both to relax and to produce a hight power output simultaneously, by relaxing those parts of the body which are not required for the move he is making. This leads to a combination of reasonable speed and economy of effort.

\section{Conclusions relating to the method of investigation.}

Without the use of the video tape recording and the simultaneous display of the oscilloscope traces it would have been extremely difficult to reach any conclusions in this investigation.

The amount of activity shown on the oscilloscope was very similar in both subject groups, and if this had been taken alone, it would have resulted in the conclusion that there was little difference in the efficiency of the subjects.

When the performances were observed on the video recording there were noticeable differences in style which were resulting in similar traces. For example, one subject who had no previous experience, showed a tendency to keep very close to the wall and as a result had to work very hard when moving his feet and showed signs of slight distress. This led to his producing traces which showed an equivalent amount of activity to that produced by the most experienced climber. However, his style was certainly less efficient and he was producing 
only fifty per cent of the power produced by the other climber.

This example illustrates how important the synchronised playing of the two recordings was to the investigation, and that without this method there may have been a mistake in the conclusions made.
The heart rate traces were used as extra comparison when examining relaxation and possible slight fear.

Therefore it can be concluded that, especially when analysing a complex activity, the combined use of equipment as investigated in this work is essential to achieve optimum results.

\section{CORRESPONDENCE}

\section{TETANUS IN SPORTSMEN}

Coroner's Court, MANCHESTER, M1 $2 P H$

29th March, 1972

Dear Sir,

\section{Sports Mortality Study}

I have just held an Inquest which I think may be of interest to you in connection with the ahove investigations.

The deceased was a young man ...... (The Coroner outlines the detailed history of the sports injury sustained by a young footballer during a tackle, with the subsequent detailed clinical history of the development and course of tetanus, with details of the post-mortem findings.) (He continues)... In his report to me (the medical specialist concerned) made a very interesting observation in the last paragraph, which I discussed with him in the box. This is what he said-

"Over the last few years there have been a number of cases of tetanus, including one other fatal case, in young
amateur footballers and I have previously put forward the view that all amateur field sports players should be
immunised against the disease. Although considerable public interest has been shown in this view it has not resulted
in much practical result. At the present time children are immunised routinely against tetanus and this has been
going on now for some 15 years so that the great bulk of schoolchildren are safe while engaging in field sports. It will
seem likely that for the next 10 years amateur footballers in the $15-25$ years age group will remain susceptible to the
disease."

This seems to me eminently sound. I gather from him that immunisation and periodic boosting are almost a part of the training routine of any professional football club, and it doesn't seem to me beyond the wit of man to extend this system to amateurs who may, because of the very different conditions in which they play the game, be at greater risk although, of course, one can contract tetanus without the intervention of broken bottles. He said that when he first raised this matter a few years ago he was much assisted by Dr. Michael Winstanley who was then M.P. for Cheadle and Gatley, who brought the matter to the notice of both the Minister of Health and the Minister for Sport, but without any effective results.

I should be most grateful for any assistance which your Association could provide in reviving this matter as it really seems to me to be very important.

Yours sincerely,

D. Summersfield

H.M. Coroner, City of Manchester 